\title{
Primary bone diffuse large B-cell lymphoma: a retrospective evaluation on 76 cases from French institutional and LYSA studies
}

Sylvain Pilorge, Stephanie Harel, Vincent Ribrag, Frédérique Larousserie, Lise Willems, Patricia Franchi, Marielle Legoff, David Biau, Philippe Anract, Christian Roux, Estelle Blanc-Autran, Richard Delarue, Christian Gisselbrecht, Nicolas Ketterer, Christian Recher, Christophe Bonnet, Frederic Peyrade, Corinne Haioun, Hervé Tilly, Gilles Salles, Pauline Brice, Didier Bouscary, Bénédicte Deau \& Jerome Tamburini

To cite this article: Sylvain Pilorge, Stephanie Harel, Vincent Ribrag, Frédérique Larousserie, Lise Willems, Patricia Franchi, Marielle Legoff, David Biau, Philippe Anract, Christian Roux, Estelle Blanc-Autran, Richard Delarue, Christian Gisselbrecht, Nicolas Ketterer, Christian Recher, Christophe Bonnet, Frederic Peyrade, Corinne Haioun, Hervé Tilly, Gilles Salles, Pauline Brice, Didier Bouscary, Bénédicte Deau \& Jerome Tamburini (2016) Primary bone diffuse large B-cell lymphoma: a retrospective evaluation on 76 cases from French institutional and LYSA studies, Leukemia \& Lymphoma, 57:12, 2820-2826, DOI: 10.1080/10428194.2016.1177180

To link to this article: http://dx.doi.org/10.1080/10428194.2016.1177180

+ View supplementary material $₫$

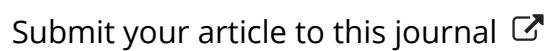

Published online: 27 Apr 2016.
View related articles $\longleftarrow$

\section{View Crossmark data $\asymp$}

Citing articles: 1 View citing articles $\asymp$ 


\title{
Primary bone diffuse large B-cell lymphoma: a retrospective evaluation on 76 cases from French institutional and LYSA studies
}

\author{
Sylvain Pilorge ${ }^{\mathrm{a}, \mathrm{b}}$, Stephanie Harel ${ }^{\mathrm{c}}$, Vincent Ribrag ${ }^{\mathrm{d}}{ }$ Frédérique Larousserie $^{\mathrm{b}, \mathrm{e}}$, Lise Willems ${ }^{\mathrm{a}, \mathrm{b}}$, \\ Patricia Franchi ${ }^{a, b}$, Marielle Legoff ${ }^{a, b}$, David Biau, ${ }^{b, f}$, Philippe Anract ${ }^{b, f}$, Christian Roux $^{b, g}$, Estelle Blanc-Autran ${ }^{\text {h }}$, \\ Richard Delaruei, Christian Gisselbrecht', Nicolas Ketterer ${ }^{k}$, Christian Recher', Christophe Bonnet ${ }^{\mathrm{m}}$, \\ Frederic Peyrade $^{n}$, Corinne Haioun $^{\circ}$, Hervé Tilly ${ }^{p}$, Gilles Salles ${ }^{q}$, Pauline Brice ${ }^{c}$, Didier Bouscary ${ }^{\mathrm{a}, \mathrm{b}}$, \\ Bénédicte Deau ${ }^{\mathrm{a}, \mathrm{b}}$ and Jerome Tamburini ${ }^{\mathrm{a}, \mathrm{b}}$
}

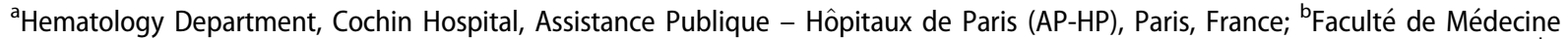
Sorbonne Paris Cité, Université Paris Descartes, Paris, France; 'Lymphoid Malignancies Unit, Saint Louis Hospital, Paris, France; ${ }^{\mathrm{d} G u s t a v e}$

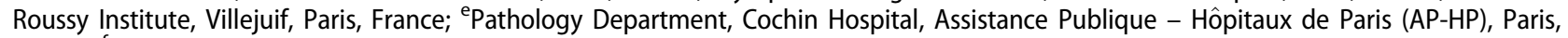
France; ${ }^{f}$ Orthopedic Surgery Department, Cochin Hospital, AP-HP, Paris, France; ${ }^{9}$ Rhumatology Department, Cochin Hospital, AP-HP, Paris, France; ${ }^{h}$ Nuclear Medicine Department, Centre Medico-Chirurgical Marie-Lannelongue, Le Plessis-Robinson, France; ${ }^{i} H e m a t o l o g y$ Department, Necker Hospital, Paris, France; 'Service Onco-Hématologie Hôpital Saint Louis, Paris, France; ${ }^{\circ}$ Clinique Bois-Cerf, Lausanne, Switzerland; 'Service d'Hématologie, Institut Universitaire du Cancer de Toulouse Oncopole, Toulouse, France; ${ }^{m}$ Département de Médecine, Service d'Hématologie Clinique, CHU Liège, Campus Universitaire du Sart-Tilman, Belgique; ${ }^{\mathrm{n} D e p a r t m e n t ~ o f ~ O n c o l o g y, ~}$ Antoine-Lacassagne Center, Nice, France; ${ }^{\circ}$ Department of Hematology, Henri Mondor University Hospital, Créteil, France; ${ }^{\mathrm{P} C e n t r e}$ HenriBecquerel, Université de Rouen, Rouen, France; ${ }^{9}$ Centre Hospitalier Lyon Sud, Service d'Hématologie, Hospices Civils de Lyon, Lyon, France
\end{abstract}

\section{ABSTRACT}

Primary bone diffuse large $\mathrm{B}$-cell lymphoma (PB-DLBCL) is a rare $\mathrm{DLBCL}$ location variant. We treated 76 PB-DLBCL patients by immuno-chemotherapy, resulting in an $84 \%$ sustained complete remission rate and a $78.9 \%$ survival over a $4.7-y e a r$ median follow-up period. Ann Arbor stage IV and high age-adjusted international prognostic index were predictive of adverse outcome in univariate analysis. In multivariate analysis using a Cox model, only aa-IPI predicted long-term survival. While based on a limited number of cases, we suggested that radiotherapy may be useful as a consolidation modality in PB-DLBCL. We also suggested that positron emission tomography/ CT scan should be interpreted with caution due to a persistent [18F]fluorodeoxyglucose [18FDG] uptake of bone lesions even after remission in some in PB-DLBCL patients. Our study based on a homogeneous cohort of PB-DLBCL patients confirmed the favorable outcome of this DLBCL variant and support the implementation of prospective clinical trials in this disease.

\section{ARTICLE HISTORY}

Received 25 November 2015 Revised 29 March 2016 Accepted 2 April 2016

\section{KEYWORDS}

aa-IPI; DLBCL; radiotherapy; rituximab; primary bone lymphoma

\section{Introduction}

Primary bone diffuse large $B$ cell lymphoma (PB$\mathrm{DLBCL}$ ) is a rare type of extranodal lymphoma accounting for less than $2 \%$ of non-Hodgkin lymphomas [1] and $3 \%$ of bone malignancies.[2] This entity includes localized PB-DLBCL characterized by a single bone lesion (stage IE) without or with (stage IIE) regional lymph node involvement, and multifocal PB-DLBCL defined by multiple bone lesions without lymphatic or visceral involvement (stage IV). PB-DLBCL is frequently revealed by pain and/or mass along skeletal structures. Femur (13-33\%), pelvis (11-15\%), humerus (11-13\%), tibia (5-20\%) and vertebrae (5-32\%) bones are frequently involved. Fractures can occur in $10 \%$ to $22 \%$ of cases at diagnosis.[3-5] In most reports, a majority of patients have a localized disease while multifocal disease is found in less than $25 \%$ of the cases.[6,7] Among bone lymphomas, DLBCL is the most commonly found (78\% to $97 \%$ of cases) and germinal and non-germinal center histological subtypes are equally represented.[8,9] Other subtypes found in a minority of cases include follicular, lymphoplasmocytic, anaplastic large cell, NK/T cell, Burkitt's lymphoma and Hodgkin lymphoma.[1,6,7,10,11] Currently, the standard of care is systemic chemotherapy - mostly the CHOP regimen combined with rituximab immunotherapy - leading to

CONTACT Bénédicte Deau benedicte.deau-fischer@aphp.fr 1 Service d'Hématologie Clinique, Hôpital Cochin, 27 rue du Faubourg Saint Jacques, 75014 Paris, France; or Jerome Tamburini 0 jerome.tamburini@aphp.fr $\mathrm{O}$ Service d'Hématologie Clinique, Hôpital Cochin, 27 rue du Faubourg Saint Jacques, 75014 Paris, France

(4) Supplemental data for this article can be accessed here.

C) 2016 Informa UK Limited, trading as Taylor \& Francis Group 


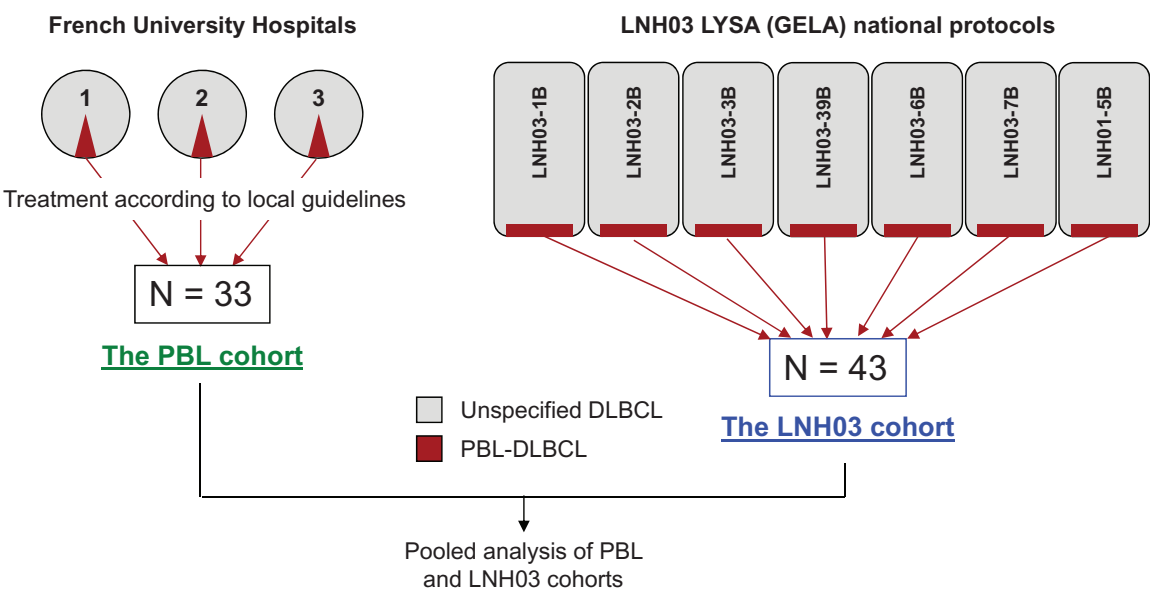

Figure 1. Flow-chart of our study including PBL and LNH03 cohorts.

a cure in a majority of patients.[12,13] Combined radio/chemotherapy strategy appeared promising in some studies but has to be evaluated more widely in PB-DLBCL.[14] In most studies, histological subtypes and clinical entities (i.e. primary versus systemic bone involvement) of lymphoma are mixed. As we believe that DLBCL with pure bone involvement may share common features and similar therapeutic response, we aimed to report here our experience on 76 cases of PB-DLBCL. The objectives of this study were to assess therapeutic response of PBL-DLBCL to immuno-chemotherapy on progression-free and overall survival (PFS and OS, respectively) and to search for clinical, biological or morphological ([18F]fluorodeoxyglucose (18FDG) positron emission tomography/CT scan) markers correlating with to PFS and OS in this cohort.

\section{Methods and patients}

We retrospectively collected data from patients treated in three French University Hospital. Inclusion criteria were stage I, II and IV primary bone (PB)-DLBCL. Exclusion criteria were all other nodal and extranodal - including bone marrow - involvement excepted for stage IE and IIE diseases. This cohort was referred to as the PBL cohort. We also addressed this question nationwide through data collected from French LYSA (formerly GELA and thereafter referred to as the LYSA cohort) cooperative group protocols. The LNH03B program of the GELA consisted of 7 prospective multicenter studies of patients with DLBCL older than age 18 years, all of which had a pathology review confirming the DLBCL diagnosis. Patients were stratified on age and age-adjusted International Prognosis Index for treatment allocation in phase II and phase III random-

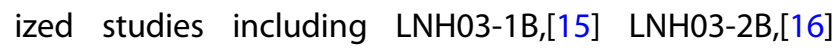
LNH03-3B,[17] LNH03-39B,[18] LNH03-6B,[19] LNH03-7B
[20] and LNH01-5B [21] (Supplemental Table 1). From these studies, we extracted data on stage I, IE, II, IIE and IV PB-DLBCL patients after LYSA scientific committee approval. Patients from these protocols were referred to as the LNH03 cohort (Figure 1). Hans score was determined retrospectively in $40(52,6 \%)$ tissue samples, 19 in the LNH03 and 21 in the PBL cohort.[22] There was no overlap in patients from PBL and $\mathrm{LNHO3}$ cohorts.

\section{Statistical analysis}

Qualitative variables (i.e. patients' characteristics and treatment strategies) were described according to the two cohorts (PBL and $\mathrm{LNHO}$ cohorts) but also as a pooled cohort. PFS was measured from the date of randomization to the date of disease progression, relapse, or death from any cause and OS from date of randomization to death from any cause. PFS and OS were analyzed using the log-rank test and expressed as Kaplan-Meier plots. Cox proportional hazards regression model were performed. Univariate analysis was done on PFS and OS to evaluate the prognostic impact of IPI stage, use of rituximab, type of chemotherapy (CHOP versus ACVBP) and post-induction PET evaluation. Multivariate analyses on PFS and OS were performed with a Cox proportional hazards regression model including the variables that were significant in univariate analysis. Differences between the results of comparative tests were considered significant if the two-sided $p$ value was less than .05 . Statistical analyses were performed using SAS 9.2 software (SAS Institute, Cary, NC).

\section{Results}

We identified 76 PB-DLBCL patients: 33 in the PBL cohort and 43 in the $\mathrm{LNHO3}$ cohort. Specific and 
Table 1. Characteristics of PB-DLBCL patients.

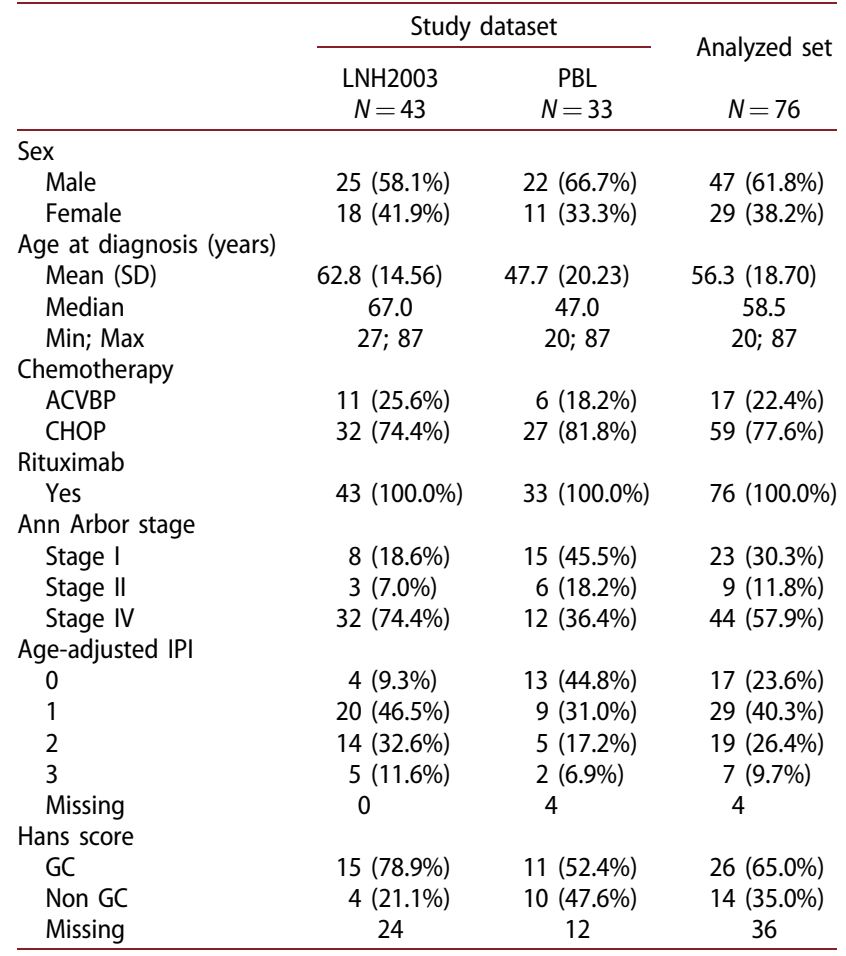

pooled characteristics of patients from PBL and $\mathrm{LNHO3}$ cohorts are provided in Table 1. There were 47 males and 29 females. Median age at diagnosis was 58. Ann Arbor stage was localized (stage I-II) in $33(42 \%)$ and disseminated (stage IV) in $44(58 \%)$ patients. Forty-six (64\%) patients had a low age-adjusted International Prognostic Index (aa-IPI) while aa-IPI was high in 26 (36\%) and unavailable for 4 patients. Hans's score available in 40/76 (53\%) patients distinguished between germinal center (CG) and non-CG in 26 (65\%) and 14 (35\%) cases, respectively. All patients received chemotherapy including ACVBP in 17 (22.4\%) or CHOP in 59 (77.6\%) patients (these chemotherapy regimens are described in Supplemental Table 2). The ACVBP regimen was developed by the French GELA group and compared favorably to $\mathrm{CHOP}$ in several clinical trials regardless concurrent use of rituximab.[16,21,23] Incorporation of immunotherapy by the anti-CD20 monoclonal antibody Rituximab into chemotherapy regimens became a standard of care for DLBCL these last 15 years.[24] In fact, all the patients of this study received rituximab combined with $\mathrm{CHOP}$ or ACVBP chemotherapy regimens. Radiotherapy was given to 15 (19.7\%) patients. For 11 of them, radiotherapy was performed as a planned consolidation therapy after immunochemotherapy according to local guidelines. These patients had mostly stage I-II disease and 10 of them experienced long-term complete remission while one patient underwent salvage chemotherapy and autologous stem cell transplantation (ASCT). Four patients received radiotherapy as a salvage therapy, generally in combination with chemotherapy and two of them successfully received ASCT (Supplemental Table 3). Among our patients, 38 (52.8\%) had post-therapy 18FDG positron emission tomography/CT (PET) (PET) evaluation, which was positive in $12(32.4 \%)$ and negative in 25 (67.6\%).

Median follow-up was 4.7 years (95\% confidence interval (Cl) 3.7-5 years; range $0.1-7.7$ years). The median OS and median PFS were not reached and 7.1 years, respectively (Figure 2). The 4-year estimated PFS and OS probability were $74.3 \%$ (Cl: $62.1-83.1 \%)$ and 80\% (Cl: 68.4-87.8\%), respectively. Overall, 12 (15.8\%) patients had relapsed or progressive disease - which were stage IV diseases for 10 (83\%) of them - while 64 (84.2\%) experienced sustained complete remission; 16 (21.1\%) patients died -8 from progressive/relapsed disease and 8 from unrelated causes - and 60 (78.9\%) are alive. Among relapsed/refractory patients, 11 received salvage therapy involving various chemotherapy regimens and in some cases RT. Three (25\%) patients achieved a complete response and successfully underwent ASCT. Two patients achieved a partial response after chemotherapy and one of them had also radiotherapy. The remaining 8 patients (66\%) were treated with chemotherapy or RT and had progressive disease (Supplemental Table 4).

In our cohort we searched for correlations between patient characteristics - including Ann Arbor stage, aaIPI, Hans score, type of treatment (ACVBP and CHOP), use of radiotherapy and post-induction $P E T$ results - and outcome. In univariate analysis, we observed a significant difference in PFS with a 4-year estimated PFS of $89.5 \%$ (Cl: 70.7-96.5\%) versus $63.4 \%$ (Cl: $46.1-76.4 \%)$ and OS of $93 \%(\mathrm{Cl}: 74.7-98.2 \%)$ versus 70.7\% (Cl: 53.7-82.4\%) for Ann Arbor stage I-II versus IV, respectively. Among our cohort of patients, two (6.3\%) deaths occurred in stage I-II and $14(31.8 \%)$ in stage IV disease $(p=0.011$, Supplemental Figure 1$)$. We also investigated the impact of aa-IPI, with an estimated 4-year PFS probability of $87.8 \%$ (Cl: 73-94.8\%) versus $47.4 \%$ (Cl: $26.5-65.7 \%)$ and 4-year OS probability of $94.8 \%$ (Cl: $80.8-98.7 \%$ ) versus $51.3 \%$ (Cl: $29.9-69.2 \%$ ) in aa-IPI $0-1$ and $2-3$, respectively. Three $(6.5 \%)$ death occurred in 0-1 aa-IPI patients and $13(50 \%)$ in 2-3 aaIPI patients $(p<0.0001$, Figure 3$)$. Also, age over 60 year-old adversely influenced prognosis as shown in Supplemental Figure 2. Conversely, Hans's score, radiotherapy and PET results had no prognosis impact in our cohort (data not shown). Concerning the type of immunochemotherapy, while no statistically significant difference was found, a trend to a better survival was observed in patients treated with RACVBP compared to 


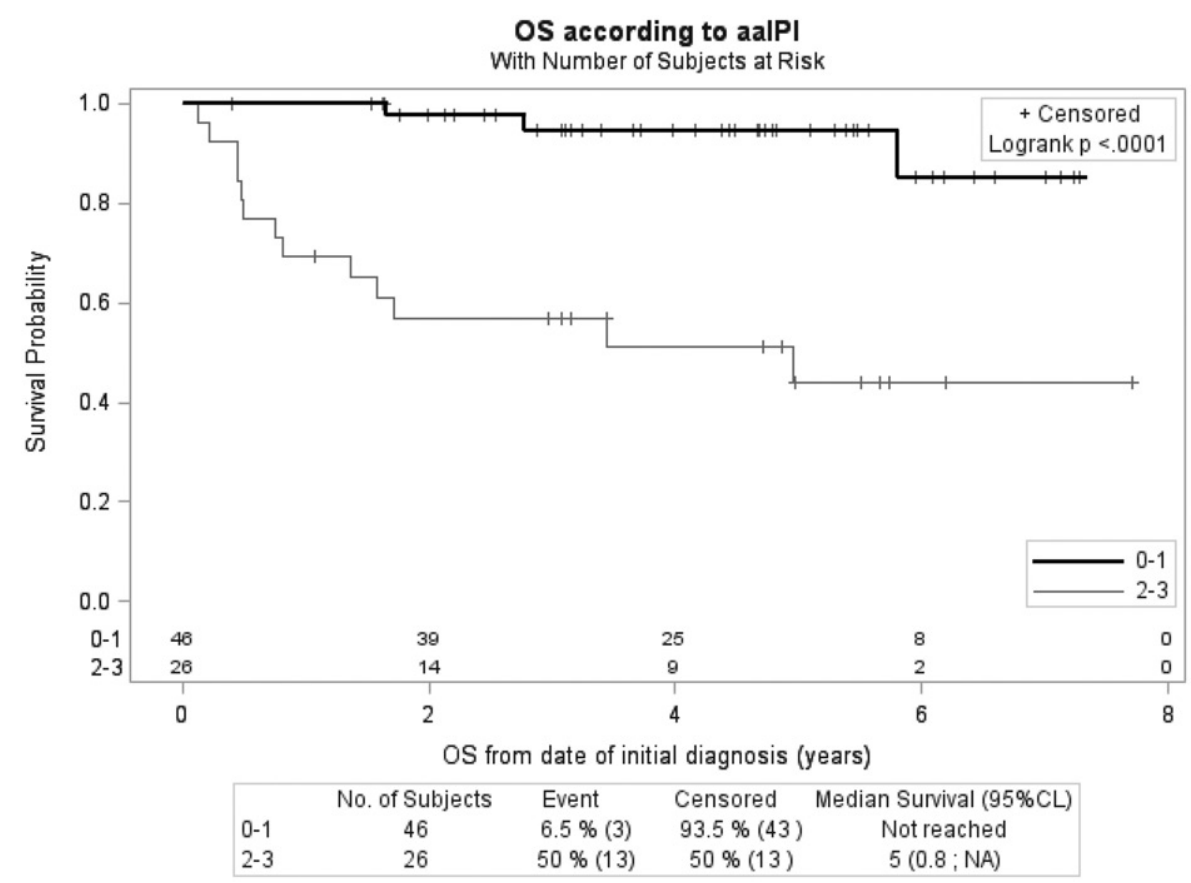

Figure 2. Survival of the 76 PB-DLBCL patients. (A) Progression-free survival (PFS) and (B) overall survival (OS) curves. The number of patients at risk is indicated at each time marker. Time-scale is in years.

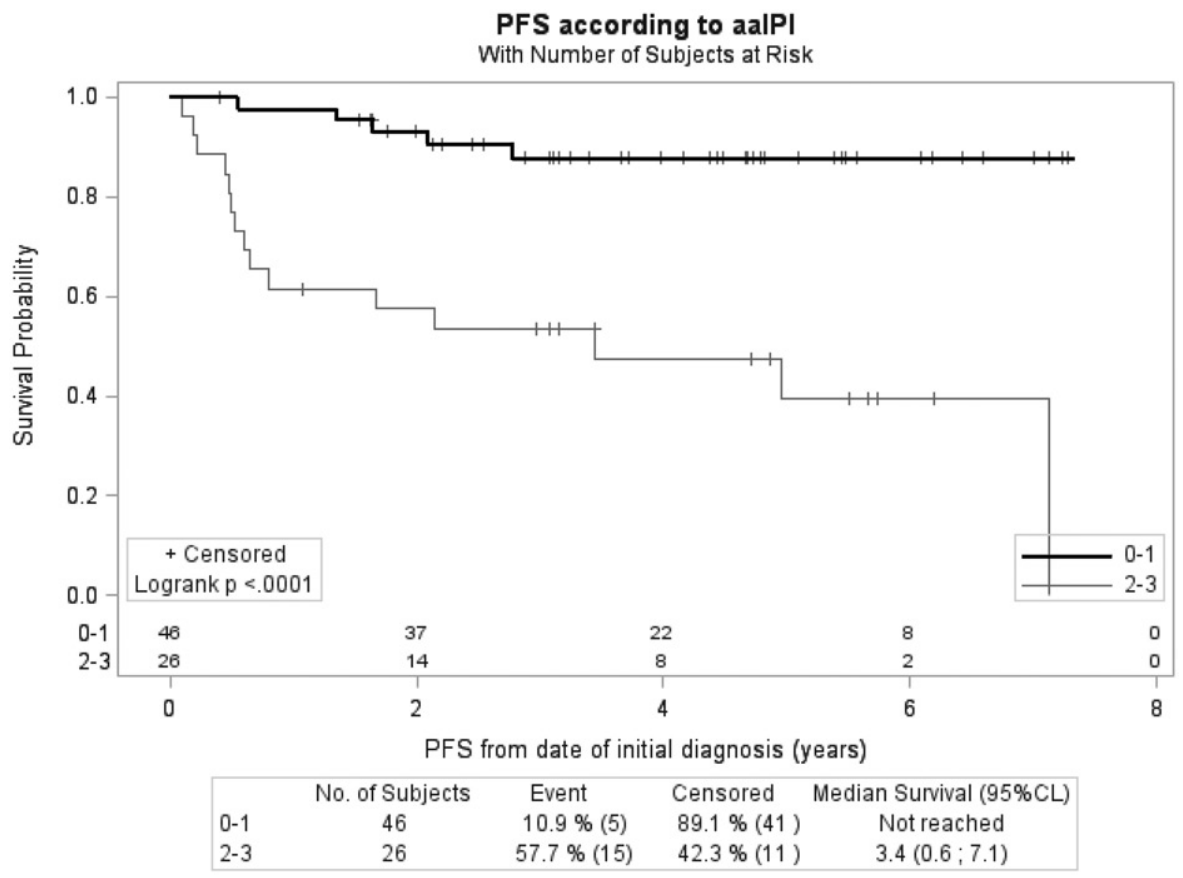

Figure 3. Survival according to aa-IPI. (A) PFS and (B) OS curves. Patients were separated based on aa-IPI score. 0-1 black line and 2-3 grey line. Comparison between survival curves is given by a log-rank test.

RCHOP (Supplemental Figure 3). In multivariate analysis, aa-IPI was the only variable demonstrating a significant impact on survival using a Cox model. Indeed, high aa-IPI score adversely impacted on PFS (hazard ratio: 11.315 ; Cl: $1.817-70.477 ; p=0.0093$ ) and OS (hazard ratio $19.752 ; \mathrm{Cl}: 1.721-226.686 ; p=0.0166)$.

\section{Discussion}

PB-DLBCL is a rare variant accounting for $1.4 \%$ to $3.8 \%$ of DLBCL included in our various $\mathrm{LNHO3}$ trials (Supplemental Table 5). While mentioned in the 2008 WHO classification,[25] PB-DLBCL is not recognized as a unique entity in contrast to other location variants 
Table 2. Summary of PB-DLBCL studies.

\begin{tabular}{|c|c|c|c|c|c|c|c|}
\hline 1st author & $N$ & $\mathrm{~A}$ & Stage & Histo & Treatment & OS & Ref. \\
\hline Rathmell & 27 & 58 & $\begin{array}{l}\text { IE: } 85 \% \\
\text { IIE: } 15 \%\end{array}$ & ND & $\begin{array}{l}\text { C+RT: } 33 \% \\
\text { RT: } 56 \% \\
\text { SC: } 11 \%\end{array}$ & $\begin{array}{l}\text { RT } 40 \% \\
\text { C+ RT } 88 \%\end{array}$ & {$[13]$} \\
\hline Dubey & 45 & ND & $\begin{array}{l}\text { IE: } 67 \% \\
\text { IIE: } 33 \%\end{array}$ & DLBCL: 91\% & $\begin{array}{l}\text { C+ RT: } 80 \% \\
\text { RT: } 11 \% \\
\text { C: } 9 \%\end{array}$ & 5 years: $68 \%$ & [1] \\
\hline Zinzani & 52 & 58 & IE/IIE: $100 \%$ & DLBCL: 85\% & $\begin{array}{l}\text { C+ RT: } 63 \% \\
\text { C: } 15 \% \\
\text { RT: } 21 \%\end{array}$ & $\begin{array}{l}9 \text { years: } 68 \% \\
\text { Relapse: } \\
\text { C+RT: } 3.5 \% \\
\text { C: } 14 \% \\
\text { RT: } 57 \%\end{array}$ & [11] \\
\hline Barbieri & 77 & 42 & $\begin{array}{l}\text { IE: } 56 \% \\
\text { IIE: } 44 \%\end{array}$ & DLBCL: 97\% & $\begin{array}{l}\text { C+ RT: } 87 \% \\
\text { RT: } 13 \%\end{array}$ & 15 years: $88.3 \%$ & [32] \\
\hline Beal & 82 & 48 & $\begin{array}{l}\text { IE: } 78 \% \\
\text { IIE: } 4 \% \\
\text { IV: } 19 \%\end{array}$ & DLBCL: 85\% & $\begin{array}{l}\text { C+ RT: } 57 \% \\
\text { RT: } 14 \% \\
\text { C: } 30 \%\end{array}$ & $\begin{array}{l}5 \text { years: } 88 \% \\
\text { C or RT: } 78 \% \\
\text { C + RT: } 96 \%\end{array}$ & [7] \\
\hline Ramadan & 131 & 63 & $\begin{array}{l}\text { IE: } 26 \% \\
\text { IIE: } 20 \% \\
\text { IV: } 71 \%\end{array}$ & DLBCL: 79\% & $\begin{array}{l}\text { C: } 44 \% \\
\text { C+ RT: } 48 \% \\
\text { SC: } 12 \%\end{array}$ & $\begin{array}{l}5 \text { years: } 62 \% \\
10 \text { years: } 41 \%\end{array}$ & {$[5]$} \\
\hline Heyning & 36 & 48 & IE/IIE: $100 \%$ & $\begin{array}{l}\text { DLBCL: } 100 \% \\
\text { GC: } 53 \% \\
\text { ABC: } 22 \% \\
\text { Other: } 25 \%\end{array}$ & $\begin{array}{l}\text { C+ RT: } 69 \% \\
\text { RT: } 14 \% \\
\text { C: } 11 \% \\
\text { Other: } 6 \%\end{array}$ & 5 years: $75 \%$ & [9] \\
\hline Alencar & 53 & 52 & $\begin{array}{l}\text { IE } 66 \% \\
\text { IIE: } 11 \% \\
\text { IVE: } 23 \%\end{array}$ & DLBCL: $83 \%$ & $\begin{array}{l}\text { C+ RT: } 62 \% \\
\text { RT: } 12 \% \\
\text { C: } 21 \%\end{array}$ & 3 years: $100 \%$ & {$[6]$} \\
\hline Cai & 116 & 50 & $\begin{array}{l}\text { IE: } 80 \% \\
\text { IIE: } 20 \%\end{array}$ & DLBCL: 78\% & $\begin{array}{l}\text { C+ RT: } 75 \% \\
\text { RT: } 13 \% \\
\text { C: } 12 \%\end{array}$ & 5 years: $76 \%$ & [10] \\
\hline Wu & 70 & 56 & $\begin{array}{l}\text { IE: } 27 \% \\
\text { IIE: } 29 \% \\
\text { IV: } 44 \%\end{array}$ & DLBCL: 74\% & $\begin{array}{l}\text { C: } 47 \% \\
\text { C+ RT: } 47 \% \\
\text { Other: } 6 \%\end{array}$ & $\begin{array}{l}5 \text { years: } 81 \% \\
10 \text { years: } 75 \%\end{array}$ & [33] \\
\hline Messina & 37 & 53 & IV: $100 \%$ & DLBCL: $100 \%$ & $\begin{array}{l}\text { C+RT: } 65 \% \\
\text { C: } 35 \%\end{array}$ & 5 years: $74 \%$ & [27] \\
\hline Bruno-Ventre & 161 & 55 & I: $87 \%$ & DLBCL: $100 \%$ & C+RT: $78 \%$ & 5 years: $75 \%$ & [34] \\
\hline Tao & 102 & 55 & I-II: 70\% & DLBCL: $100 \%$ & $\begin{array}{l}\text { C+RT: } 66 \% \\
\text { Rituximab: } 72 \%\end{array}$ & 5 years: $82 \%$ & [14] \\
\hline Pilorge & 76 & 56 & $\begin{array}{l}\text { I-II: } 42 \% \\
\text { IV: } 58 \%\end{array}$ & DLBCL: $100 \%$ & $\begin{array}{l}\text { Riyuximab: } 100 \% \\
\text { RT: } 20 \%\end{array}$ & 6 years: $71 \%$ & \\
\hline
\end{tabular}

$N$ : number of patients; A: median age; Stage: stage according to Ann Arbor classification; Histo: histological informations; OS: overall survival; Ref: reference; ND: not done; C: chemotherapy; RT: radiation therapy; SC: supportive care.

such as primary mediastinal, central nervous system and "leg-type" cutaneous DLBCL.[26] Indeed, PB-DLBCL does no share unique phenotypic or gene expression profiling features or specific response to therapy and is therefore not considered separately in clinical trials.

Several retrospective studies reported PB lymphomas separately and suggested that these topographic variants may have a seemingly favorable prognostic particularly when combining chemotherapy and radiation therapy (Table 2).[7,11,13,27] However, these studies report heterogeneous data and while DLBCL is the most frequently described histological subtype, other lymphomas are reported including follicular or anaplastic types. In contrast to most studies (Table 2), we excluded from our analysis non-DLBCL lymphomas. Moreover, therapeutic option used may also markedly differ among individual cohorts. In our current study, we focused on DLBCL with pure bone involvement treated homogeneously with either CHOP or ACVBP regimens in combination with rituximab in all cases.
As PB-DLBCL is a very rare entity, we collected cases across three University Hospitals particularly involved in bone diseases (the PBL cohort) and also nationwide through the LNHO3 database from the LYSA study group including seven prospective clinical trials on DLBCL (the LNH03 cohort). The patients from these two cohorts displayed similar clinical characteristics except concerning stage I diseases, which were generally excluded from $\mathrm{LNH} 03$ studies except for $\mathrm{LNH} 03-7 \mathrm{~B}$

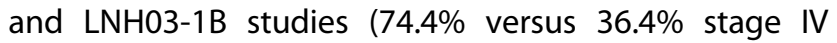
diseases in the $\mathrm{LNHO3}$ and PBL cohorts, respectively, Table 1). In fact, this difference may explains the better outcome observed in the PBL cohort compared to the LYSA cohort (PFS $84.8 \%$ versus $65.1 \%$ and OS $90.9 \%$ versus $69.8 \%$, respectively, Supplemental Figure 4) and was not apparent after multivariate analysis. Similar to other studies, we found that PB-DLBCL had a favorable outcome as $78.9 \%$ of the patients were alive and in complete remission with a median follow-up of almost five years. These results are superior to those observed 
in DLBCL clinical trials generally ranging from $60 \%$ to $70 \%$ OS $[1,5,10,11]$ and are in agreement with studies specifically focusing on PB-DLBCL with survival probabilities ranging from $68 \%$ to $100 \%$ (Table 2 ). In univariate analysis, we found that age over 60, advanced Ann Arbor stage and high aa-IPI adversely impacted on prognosis. After multivariate analysis, the only predictive marker for PFS and OS among our cohort was aaIPI.

In DLBCL, PET performed at the end of treatment has shown a high predictive value for PFS and OS.[28] Post-treatment persistent 18FDG uptake was found in $32 \%$ of evaluable patients, which was higher than expected compared to up to $20 \%$ of PET positivity in most DLBCL studies.[28] We did not detect a prognostic impact of post-treatment PET positivity in our current study. However, only $50 \%$ of patients had a metabolic response assessment which limited the robustness of our conclusions concerning PET evaluation in PB-DLBCL. In a limited number of patients $(n=8)$ from the PBL cohort, we found that in longterm follow-up (between 6 and 24 months after treatment completion), PET was negative or with SUV below the background noise, while magnetic resonance imaging (MRI) was still abnormal (data not shown). These particularities might be due to the particular course of bone healing. These results require further validation in larger/prospective cohorts but suggest that outside of clinical trials, PET scan positivity should not be used as a decision marker for salvage therapy regardless the overall context, as suggested by other reports.[29]

The role of radiation therapy (RT) remains a matter of debate in DLBCL as a consolidation modality after chemotherapy $[5,14,30]$ In our study, post-induction RT was given to 11 (33\%) patients from the PBL cohort but was not part of any $\mathrm{LNHO3}$ protocol, preventing any relevant comparison of survival data regarding RT. However, 10 of the 11 patients of the PBL cohort mostly localized diseases - treated with radiotherapy as a consolidation strategy after immunochemotherapy experienced long-term complete remission, suggesting a potential favorable impact of this strategy. This hypothesis is supported by recent data by Tao and colleagues, suggesting that RT may be useful as a consolidation modality after conventional immunochemotherapy in PB-DLBCL.[14] In a large study on DLBCL with skeletal involvement (which included 52 cases of PB-DLBCL), Held and coworkers also demonstrated a positive impact of radiotherapy on survival.[31] The question of RT as a therapeutic modality in PB-DLBCL - in combination with immunochemotherapy - may represents a pivotal question for future prospective clinical trials.

In our current study, we show that PB-DLBCL demonstrate a good prognosis when treated by immuno-chemotherapy. In addition, we suggest that radiotherapy may be useful in PB-DLBCL and that PET analysis should be used with caution as persistent 18FDG uptake may not necessarily implies treatment failure. Building on previous reports highlighting the specificities of PB-DLBCL particularly in terms of favorable outcome, our current study emphasizes the need for PB-DLBCL prospective clinical trials in the future.

\section{Acknowledgments}

We thank the whole LYSARC team - and especially Sami Boussetta - for their contribution to this work. We also thank all the clinicians involved in the LNHO3B program and those from Cochin, Saint Louis and Institut Gustave Roussy hospitals that provided care to the patients.

Potential conflict of interest: Disclosure forms provided by the authors are available with the full text of this article at http://dx.doi.org/10.1080/10428194.2016.1177180.

\section{References}

[1] Dubey P, Ha CS, Besa PC, et al. Localized primary malignant lymphoma of bone. Int J Radiat Oncol Biol Phys. 1997;37:1087-1093.

[2] Limb D, Dreghorn C, Murphy JK, et al. Primary lymphoma of bone. Int Orthop. 1994;18:180-183.

[3] Carbone PP, Kaplan HS, Musshoff K, et al. Report of the committee on Hodgkin's disease staging classification. Cancer Res. 1971;31:1860-1861.

[4] Lister TA, Crowther D, Sutcliffe SB, et al. Report of a committee convened to discuss the evaluation and staging of patients with Hodgkin's disease: Cotswolds meeting. J Clin Oncol. 1989;7:1630-1636.

[5] Ramadan KM, Shenkier T, Sehn LH, et al. A clinicopathological retrospective study of 131 patients with primary bone lymphoma: a population-based study of successively treated cohorts from the British Columbia cancer agency. Ann Oncol. 2007;18:129-135.

[6] Alencar A, Pitcher D, Byrne G, et al. Primary bone lymphoma-the university of Miami experience. Leuk Lymphoma. 2010;51:39-49.

[7] Beal K, Allen L, Yahalom J. Primary bone lymphoma: treatment results and prognostic factors with long-term follow-up of 82 patients. Cancer. 2006;106:2652-2656.

[8] Bhagavathi S, Micale MA, Les $\mathrm{K}$, et al. Primary bone diffuse large B-cell lymphoma: clinicopathologic study of 21 cases and review of literature. Am J Surg Pathol. 2009;33:1463-1469.

[9] Heyning FH, Hogendoorn PC, Kramer $\mathrm{MH}$, et al. Primary lymphoma of bone: extranodal lymphoma with favourable survival independent of germinal 
centre, post-germinal centre or indeterminate phenotype. J Clin Pathol. 2009;62:820-824.

[10] Cai L, Stauder MC, Zhang YJ, et al. Early-stage primary bone lymphoma: a retrospective, multicenter rare cancer network (RCN) study. Int J Radiat Oncol Biol Phys. 2012;83:284-291.

[11] Zinzani PL, Carrillo G, Ascani S, et al. Primary bone lymphoma: experience with 52 patients. Haematologica. 2003;88:280-285.

[12] Messina C, Christie D, Zucca E, et al. Primary and secondary bone lymphomas. Cancer Treat Rev. 2015;41:235-246.

[13] Rathmell AJ, Gospodarowicz MK, Sutcliffe SB, et al. Localised lymphoma of bone: prognostic factors and treatment recommendations. The princess Margaret hospital lymphoma group. $\mathrm{Br} J$ Cancer. 1992;66:603-606.

[14] Tao R, Allen PK, Rodriguez A, et al. Benefit of consolidative radiation therapy for primary bone diffuse large B-cell lymphoma. Int J Radiat Oncol Biol Phys. 2015;92:122-129.

[15] Ketterer N, Coiffier B, Thieblemont C, et al. Phase III study of ACVBP versus ACVBP plus rituximab for patients with localized low-risk diffuse large B-cell lymphoma (LNH03-1B). Ann Oncol. 2013;24:1032-1037.

[16] Recher C, Coiffier B, Haioun C, et al. Intensified chemotherapy with ACVBP plus rituximab versus standard $\mathrm{CHOP}$ plus rituximab for the treatment of diffuse large B-cell lymphoma (LNH03-2B): an open-label randomised phase 3 trial. Lancet. 2011;378:1858-1867.

[17] Fitoussi O, Belhadj K, Mounier N, et al. Survival impact of rituximab combined with ACVBP and upfront consolidation autotransplantation in high-risk diffuse large B-cell lymphoma for GELA. Haematologica. 2011;96:1136-1143.

[18] Delarue R, Tilly $H$, Mounier N, et al. Dose-dense rituximab-CHOP compared with standard rituximab-CHOP in elderly patients with diffuse large B-cell lymphoma (the LNH03-6B study): a randomised phase 3 trial. Lancet Oncol. 2013;14:525-533.

[19] Peyrade F, Jardin F, Thieblemont C, et al. Attenuated immunochemotherapy regimen (R-miniCHOP) in elderly patients older than 80 years with diffuse large Bcell lymphoma: a multicentre, single-arm, phase 2 trial. Lancet Oncol. 2011;12:460-468.

[20] Copie-Bergman C, Gaulard P, Leroy K, et al. Immunofluorescence in situ hybridization index predicts survival in patients with diffuse large B-cell lymphoma treated with R-CHOP: a GELA study. J Clin Oncol. 2009;27:5573-5579.

[21] Reyes F, Lepage E, Ganem G, et al. ACVBP versus $\mathrm{CHOP}$ plus radiotherapy for localized aggressive lymphoma. N Engl J Med. 2005;352:1197-1205.

[22] Hans CP, Weisenburger DD, Greiner TC, et al. Confirmation of the molecular classification of diffuse large B-cell lymphoma by immunohistochemistry using a tissue microarray. Blood. 2004;103:275-282.
[23] Tilly $H$, Lepage $E$, Coiffier $B$, et al. Intensive conventional chemotherapy (ACVBP regimen) compared with standard CHOP for poor-prognosis aggressive nonHodgkin lymphoma. Blood. 2003;102:4284-4289.

[24] Coiffier B, Lepage E, Briere J, et al. CHOP chemotherapy plus rituximab compared with $\mathrm{CHOP}$ alone in elderly patients with diffuse large-B-cell lymphoma. N Engl J Med. 2002;346:235-242.

[25] Fletcher CDM, Krishnan UK, Mertens F. Pathology and genetics of tumors of soft tissue and bone: World Health Organization classification of tumours. Lyon, France: IARC Press; 2002.

[26] Campo E, Swerdlow SH, Harris NL, et al. The 2008 WHO classification of lymphoid neoplasms and beyond: evolving concepts and practical applications. Blood. 2011;117:5019-5032.

[27] Messina C, Ferreri AJ, Govi S, et al. Clinical features, management and prognosis of multifocal primary bone lymphoma: a retrospective study of the international extranodal lymphoma study group (the IELSG 14 study). Br J Haematol. 2014;164:834-840.

[28] Mamot C, Klingbiel D, Hitz F, et al. Final results of a prospective evaluation of the predictive value of interim positron emission tomography in patients with diffuse large B-cell lymphoma treated with R-CHOP-14 (SAKK 38/07). J Clin Oncol. 2015;33:2523-2529.

[29] Ng AP, Wirth A, Seymour JF, et al. Early therapeutic response assessment by (18)FDG-positron emission tomography during chemotherapy in patients with diffuse large B-cell lymphoma: isolated residual positivity involving bone is not usually a predictor of subsequent treatment failure. Leuk Lymphoma. 2007;48:596-600.

[30] Vargo JA, Gill BS, Balasubramani GK, et al. Treatment selection and survival outcomes in early-stage diffuse large B-cell lymphoma: do we still need consolidative radiotherapy? J Clin Oncol. 2015;33:3710-3717.

[31] Held G, Zeynalova S, Murawski N, et al. Impact of rituximab and radiotherapy on outcome of patients with aggressive B-cell lymphoma and skeletal involvement. J Clin Oncol. 2013;31:4115-4122.

[32] Barbieri E, Cammelli S, Mauro F, et al. Primary nonHodgkin's lymphoma of the bone: treatment and analysis of prognostic factors for Stage I and Stage II. Int J Radiat Oncol Biol Phys 2004;59:760-764.

[33] Wu H, Zhang L, Shao H, et al. Prognostic significance of soft tissue extension, international prognostic index, and multifocality in primary bone lymphoma: a single institutional experience. $\mathrm{Br} J$ Haematol. 166:60-68.

[34] Bruno Ventre $M$, Ferreri AJ, Gospodarowicz $M$, et al. Clinical features, management, and prognosis of an international series of 161 patients with limited-stage diffuse large B-cell lymphoma of the bone (the IELSG14 study). Oncologist. 19:291-298. 